\title{
Reviving a national prevention agenda is key to sustainability of health care in Canada
}

\author{
Robert Strang MD MHSC, Perry Kendall MBBS MHSC, Andre Corriveau MD; on behalf of the provincial/ \\ territorial chief medical officers of health with the exception of Quebec*
}

Cite as: CMAJ 2017 October 10;189:E1250-1. doi: 10.1503/cmaj.170694

$\mathbf{R}$ ecent health funding agreements between the Canadian federal, provincial and territorial governments have centred on overall funding, with additional targeted funding for home care, mental health and addictions. However, if objectives related to fiscal sustainability, quality health care and improved population health are to be achieved, a greater focus on preventive and public health measures will be required.

A healthier population directly and indirectly contributes to broad economic sustainability. Despite historical improvements in population health through improved nutrition, provision of safe drinking water and sewage removal, childhood vaccines and access to medical care, much of our disease burden today remains rooted in socioeconomic and environmental factors. Gains in health have not been shared equally. Many indigenous communities, people with mental health conditions and poorer people continue to have persistently higher rates of morbidity and death. Climate change ${ }^{1}$ and increasingly inequitable societies $^{2}$ are the biggest threats to our collective health. How can we address these problems?

In 2010, "Creating a Healthier Canada: Making Prevention a Priority. A Declaration on Prevention and Promotion from Canada's Ministers of Health and Health Promotion/Healthy Living"3 highlighted how a strong focus on prevention is a critical hallmark of a quality health care system. As we progress beyond renegotiation of the 2004 Health Accord, we implore health ministers to reaffirm commitment to the principles outlined in the declaration, as well as to a whole-of-government approach to safe, vibrant and sustainable communities. Health ministers should also show strong support for policies and programs that are not related to health care but that will have direct effects on the health of Canadians: poverty reduction, affordable housing, community infrastructure investment (such as mass transit and water/sewage systems) and climate change initiatives.

Analytic and collaborative capacity must continue to be built at local, provincial and national levels to advance comprehensive prevention initiatives. Ensuring that population health status and health inequities at all levels can be effectively monitored is key, particularly for First Nations, Inuit and Metis communities. We also need to build public health surveillance and emergency response

\section{KEY POINTS}

- If national objectives related to fiscal sustainability, quality health care and improved population health are to be achieved, a greater focus on preventive and public health measures will be required.

- A strong focus on prevention is a critical hallmark of a quality health care system.

- Addressing high rates of chronic disease and cancer, and the disproportionate effects on certain subpopulations, will require addressing their underlying socioeconomic causes.

- Return on investment is likely to be greatest from policy initiatives outside the health care system.

- A healthier population directly and indirectly contributes to broad economic sustainability.

capabilities at the regional, provincial and federal levels as part of climate change adaptation and efforts to address global infectious disease threats.

Addressing these infectious disease threats and ensuring protection for all Canadians requires a strengthened collective commitment to a national immunization strategy, with a focus on ensuring secure vaccine supplies, addressing vaccine hesitancy and having a comprehensive understanding of vaccination coverage rates for all Canadian communities through the development of vaccine registries.

Addressing today's epidemics of noncommunicable diseases can, in part, be achieved through legislation, policies and programs that make the healthier choice the easier and more affordable choice. These initiatives need to be supplemented by appropriately scaled investments in health literacy, clinical prevention and chronic disease management, with a continued focus on the federal, provincial and territorial framework for action to promote healthy weights. ${ }^{4}$ The Healthy Eating Strategy announced by Health Canada in 2016 contained commitments to strengthen regulations on sodium and trans fats, improve labelling of food and limit marketing of unhealthy foods and beverages to children. It provides an opportunity for provincial 
and territorial governments to coordinate their own initiatives in food policy, creating a synergy that could achieve great impact. Furthermore, we must not lose our focus on tobacco control, and a collective commitment to reducing rates of tobacco use from the current national rate of $15 \%$ to $5 \%$ by 2035 would be a good first step. However, to fully address our high rates of chronic disease and cancer, and the disproportionate effects on certain subpopulations, we will need to address the underlying socioeconomic causes.

Substance use and addiction create substantial health, social and justice issues in all our communities. Legalization of cannabis must be done with regulations and policies that prioritize the protection of public health and safety. Our approach to alcohol should be viewed through that same lens. Addressing both illegal and prescription problematic substance use must be done using a harm reduction approach that acknowledges addiction as a health and social, rather than a criminal, issue.

The Mental Health Commission of Canada ${ }^{5}$ noted that Canada has a tremendous burden of mental health problems with unmet service needs. Investment in and monitoring of the elements of the Positive Mental Health Survellance Indicator Framework now under development by the Pan-Canadian Public Health Network (http://infobase.phac-aspc.gc.ca/positive-mental-health/) would be a good start toward improving the mental health of Canadians.

Advancing this vision of a population health agenda necessitates a shift to a focus on health in its broadest sense rather than just on health care. Increasing investments in health care within the context of tight resource constraints arguably has a negative impact on population health by preventing investments in areas such as education, social supports and housing. Cost savings from preventive measures ${ }^{6}$ would allow for re-investment in innovative care models, new diagnostic and treatment approaches, building public health capacity and investments outside the health care system within existing resources. The return on investment in these areas is likely to be greatest from policy initiatives outside the health care system. ${ }^{6}$

Over the last decade, considerable progress was made in building the foundations for this change. The 2004 Health Accord included a commitment to develop a Pan-Canadian Healthy Living Strategy ${ }^{7}$ that prioritized healthy living, obesity reduction, injury prevention, mental health promotion and reduction of health inequities. Since 2005, the Pan-Canadian Public Health Network has coordinated federal, provincial and territorial health sector work on prevention and health protec- tion initiatives. It can be argued that this network is the most successful ongoing formal mechanism for collaboration on health at the federal, provincial and territorial levels. Its efforts should be strengthened and expanded going forward.

\section{References}

1. Global change and public health: addressing the ecological determinants of health. Ottawa: Canadian Public Health Association; 2015. Available: www.cpha. ca/sites/default/files/assets/policy/edh-discussion_e.pdf (accessed 2017 Aug. 8).

2. World conference on the social determinants of health: meeting report. Brazil: World Health Organization; 2011. Available: www.who.int/sdhconference/ resources/Conference_Report.pdf?ua=1 (accessed 2017 Aug. 8).

3. Creating a healthier Canada: making prevention a priority. A declaration on prevention and promotion from Canada's Ministers of Health and Health Promotion/Healthy Living. Ottawa: Public Health Agency of Canada; 2010. Available: www.phac-aspc.gc.ca/hp-ps/hl-mvs/declaration/pdf/dpp-eng.pdf (accessed 2017 Aug. 3).

4. Curbing childhood obesity: a federal, provincial and territorial framework for action to promote healthy weights. Ottawa: Public Health Agency of Canada; 2011. Available: www.canada.ca/content/dam/phac-aspc/migration/phac-aspc/ hp-ps/hl-mvs/framework-cadre/pdf/ccofw-eng.pdf (accessed 2017 Aug. 8).

5. Changing direction changing lives: the mental health strategy for Canada. Calgary: Mental Health Commission of Canada; 2012. Available: www. mentalhealthcommission.ca/sites/default/files/MHStrategy_Strategy_ENG.pdf (accessed 2017 Aug. 4).

6. Masters R, Anwar E, Collins B, et al. Return on investment of public health interventions: a systematic review. J Epidemiol Community Health 2017;71:827-34.

7. The Integrated Pan-Canadian Health Living Strategy. Ottawa: Public Health Agency of Canada; 2005. Available: www.canada.ca/content/dam/phac-aspc/migration/ phac-aspc/hp-ps/hl-mvs/ipchls-spimmvs/pdf/ipchls-spimmvs-eng.pdf (accessed 2017 Aug. 8).

\section{Competing interests: None declared.}

This article has been peer reviewed.

Affiliations: Chief Medical Officer of Health (Strang), Nova Scotia; Provincial Health Officer (Kendall), British Columbia; Chief Public Health Officer (Corriveau), Northwest Territories

*Dr. Perry Kendall (British Columbia); Dr. Karen Grimsrud (Alberta); Dr. Saqib Shahab (Saskatchewan); Dr. Elise Weiss (Manitoba); Dr. David Williams (Ontario); Dr. Jennifer Russell (New Brunswick); Dr. Robert Strang (Nova Scotia); Dr. Heather Morrison (Prince Edward Island); Dr. David Allison (Newfoundland and Labrador); Dr. Brendan Hanley (Yukon); Dr. André Corriveau (Northwest Territories); Dr. Kim Barker (Nunavut)

Contributors: All of the authors contributed to the development and design of the article, participated in drafting the manuscript and revising it for important intellectual content, gave final approval of the version to be published and agreed to be accountable for all aspects of the work.

Correspondence to: Robert Strang, robert.strang@novascotia.ca 